\title{
How well do Australian women comply with dietary guidelines?
}

\author{
Kylie Ball ${ }^{1, *}$, Gita D Mishra ${ }^{2}$, Christopher W Thane ${ }^{2}$ and Allison Hodge ${ }^{3}$ \\ ${ }^{1}$ School of Health Sciences, Deakin University, 221 Burwood Highway, Burwood, Victoria 3125, Australia: \\ ${ }^{2}$ MRC Human Nutrition Research, Elsie Widdowson Laboratory, Fulbourn Road, Cambridge CB1 9NL, UK: ${ }^{3}$ The \\ Cancer Council of Victoria, Carlton, Victoria 3053, Australia
}

Submitted 10 July 2003: Accepted 3 September 2003

\begin{abstract}
Objective: To investigate the proportion of middle-aged Australian women meeting national dietary recommendations and its variation according to selected sociodemographic and behavioural characteristics.

Design: This cross-sectional population-based study used a food-frequency questionnaire to investigate dietary patterns and compliance with 13 commonly promoted dietary guidelines among a cohort of middle-aged women participating in the Australian Longitudinal Study on Women's Health.

Setting: Nation-wide community-based survey.

Subjects: A total of 10561 women aged 50-55 years at the time of the survey in 2001. Results: Only about one-third of women complied with more than half of the guidelines, and only two women in the entire sample met all 13 guidelines examined. While guidelines for meat/fish/poultry/eggs/nuts/legumes and 'extra' foods (e.g. ice cream, chocolate, cakes, potatoes, pizza, hamburgers and wine) were met well, large percentages of women $(68-88 \%)$ did not meet guidelines relating to the consumption of breads, cereal-based foods and dairy products, and intakes of total and saturated fat and iron. Women working in lower socio-economic status occupations, and women living alone or with people other than a partner and/or children, were at significantly increased risk of not meeting guidelines.

Conclusions: The present results indicate that a large proportion of middle-aged Australian women are not meeting dietary guidelines. Without substantial changes in their diets, and help in making these changes, current national guidelines appear unachievable for many women.
\end{abstract}

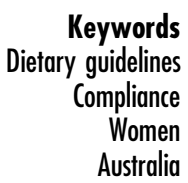

Increasing knowledge of the role of diet in the aetiology of major causes of morbidity and mortality ${ }^{1}$ has led, in many countries, to the development and promotion of dietary guidelines aimed at achieving specified dietary goals and improving the dietary habits and nutritional status of populations ${ }^{2,3}$. In Australia, for instance, the National Health and Medical Research Council has promoted evidence-based dietary advice to the public through the development of Australian dietary guidelines ${ }^{3}$. The Australian Guide to Health Eating ${ }^{4}$ has also been used to encourage health-promoting food choices.

Regional studies conducted in Australia during the 1980s suggested, however, that relatively small percentages (less than 30\%) of the population achieved Australian dietary guidelines ${ }^{5-7}$. For example, randomly selected Australian adults were asked whether they practised each of 11 specific health-promoting dietary activities $^{5}$. About one-third claimed to be practising each of the activities, with women and tertiary-educated persons faring better than men and persons with lower education level. Over one-third of the sample did not practise any of the dietary activities.
A more recent study of young Australians found that substantial proportions were not meeting dietary guidelines for fat, saturated fat or fibre intake, or achieving Recommended Dietary Intakes for zinc, calcium, magnesium and iron ${ }^{8}$. However, this study used a relatively small, non-representative sample of 246 undergraduate students. Another Australian study ${ }^{9}$ suggested that increased promotion of population-based dietary and health messages was associated with subsequent improvements in dietary behaviour in the direction of the dietary guidelines. However, that study used a small sample based in only one city (Brisbane) and hence could not take into account known regional variations in dietary intake established previously ${ }^{10}$.

In order to monitor progress towards national dietary recommendations, food consumption should be assessed at the population level. However, the assessment of dietary intake in populations is complicated and expensive to conduct, and thus in many countries, including Australia, there are limited sources of comprehensive population data on diet and nutrition. The chief sources of data used for national food and nutrition 
monitoring among individuals and subgroups in Australia are the infrequently conducted national dietary and nutrition surveys ${ }^{11-14}$. Analyses of data from the two most recent national nutrition surveys in Australia, in $1983^{11}$ and $1995^{13,14}$, suggested that diets had changed significantly between the 1980s and 1990s in directions consistent with dietary recommendations (e.g. lower fat and sugar intakes, and higher consumption of cerealbased foods), although large proportions of the population, particularly in certain population subgroups (e.g. low socio-economic groups), still did not meet the recommendations ${ }^{15,16}$. However, data from these two surveys are based on 24-hour dietary recall, and hence may not represent habitual intakes. Presently there are no more recent (post-1995) published national population nutrition data in Australia with which to examine compliance with recently promoted dietary recommendations ${ }^{3,4}$.

Middle-aged women are one population group at risk of not meeting dietary guidelines. Findings of the 1995 Australian National Nutrition Survey (NNS) showed that, among women aged 45-64 years, mean daily consumption of fruit and vegetables was 1.1 and 3.4 servings, respectively, well below the two fruit and five vegetable servings recommended ${ }^{14}$. Mean daily consumption of dairy foods such as milk, yoghurt and cheese was below one standard serving per day, short of the recommended two or more daily servings. Consumption of other food groups that adults are encouraged to consume regularly, including breakfast cereals and fish, was also low among women in the NNS, while saturated fat intake was above recommended levels.

The Australian Longitudinal Study on Women's Health (ALSWH) provides a new source of diet and nutrition data for a large, nation-wide, population-representative community sample of women. Currently, dietary data are available for women in the 'mid-aged' cohort (aged 45-50 years at Survey 1, in 1996). Distributions of food and nutrient intakes among the cohort of mid-aged women in the ALSWH at Survey 3 are reported in a separate paper (in preparation). The present paper describes the dietary habits of the mid-aged cohort of Australian women, in relation to the food-based dietary guidelines that were current at the time of the survey ${ }^{17-20}$ and selected recommendations from The Australian Guide to Healthy Eating ${ }^{4}$. It also investigates how compliance with guidelines varies across sociodemographic subgroups.

\section{Methods}

Data used in the present study were derived from the midaged cohort of the ALSWH, for which full details of recruitment and methods are provided elsewhere ${ }^{21}$. Briefly, participants were selected at random from all over Australia, using the national Medicare health insurance database, with purposeful over-representation of women living in rural and remote areas. In 1996, 14065 middle-aged women ( $53.5 \%$ of those selected) responded to the mailed Survey 1 . The sample was reasonably representative of Australian women in this age group ${ }^{21}$. Subsequent surveys for the mid-aged cohort were conducted in 1998 (Survey 2) and 2001 (Survey 3). The present study used data from Survey 3 , which included a dietary component.

\section{Study sample}

The study sample for the present paper consisted of the 10561 middle-aged women (50-55 years at Survey 3) who provided complete nutrient data in Survey 3. Of the total sample completing Survey 1 in $1996(n=14099), 383$ women provided no contact details, 21 became too frail to respond and 102 died prior to Survey 3. Excluding these women, the overall response rate for Survey 3 ( $n=11202$ ) was $82 \%$ of Survey 1 respondents. These attrition rates are similar to those obtained in other longitudinal population-based cohort studies ${ }^{22,23}$.

\section{Dietary assessment}

Diet was assessed using The Cancer Council of Victoria's food-frequency questionnaire (FFQ), full details of which are provided elsewhere ${ }^{24,25}$. This FFQ assesses usual consumption (on a 10-point scale from 'never' to 'three or more times per day') of 74 food and six alcoholic beverage items over the previous 12 months. These were converted to daily equivalents for statistical analyses. Photographs of different portion sizes are included in the FFQ to assist in calculating nutrient intakes, which were computed using software developed by The Cancer Council of Victoria based on the NUTTAB95 nutrient composition ${ }^{26}$. The FFQ has been validated against weighed food records and found to be useful in the assessment of habitual intake in the Australian population ${ }^{25}$. For alcohol intake, an additional question asked 'Over the last 12 months, on days when you were drinking, how many glasses of beer, wine and/or spirits altogether did you usually drink?' The response options ranged from ' 1 ' up to ' 10 or more' and were assigned the corresponding code from 1 to 10 for analysis.

'Compliance' with a number of dietary guidelines and nutrient recommendations was assessed using indicators that described key aspects of food and nutrition relevant to current guidelines ${ }^{16}$. The guidelines assessed, and the indicators used for each of these, are shown in the Appendix. It was not possible to assess all guidelines currently promoted in Australia. For instance, 'Enjoy a wide variety of nutritious foods' was considered impossible to assess quantitatively. For the guideline 'Eat only a moderate amount of sugars and food containing added sugars', data were not available on intakes of sugars added during processing by the food industry. For guidelines $1-6$, daily equivalent consumption of items in each of the food groups (e.g. fruits) were summed to give a total 
number of servings per day; for example, two slices of bread or one bread roll is counted as one serving. The FFQ did not permit calculation of exact serving sizes for all foods and hence, by necessity, these six guidelines were based on the assumption that each eating occasion involved consumption of one serving. For guideline 7 (alcohol), the indicator was the product of the number of glasses of alcoholic drinks consumed on days when alcohol was consumed and the frequency (expressed as a daily equivalent) of alcohol consumption. The latter was calculated as the sum of the consumption frequencies of six types of alcoholic beverage (up to a maximum limit of consuming alcohol every day). For guidelines 8-13, nutrient estimates were used as indicators. For the indicators of fat and sugar intake, percentage energy intake derived from these nutrients was calculated by converting grams to kilojoules $(1 \mathrm{~g}$ fat $=37 \mathrm{~kJ} ; 1 \mathrm{~g}$ sugar $=16 \mathrm{~kJ}$ ). The FFQ does not include intakes of added salt, so the reported sodium intakes are likely to be conservative. Since dietary guidelines are intended to be considered as a coherent set of advice, rather than individual guidelines in isolation, the present study also assessed overall 'compliance', examining the proportions of women who met at least half (i.e. seven or more) of the 13 guidelines.

\section{Sociodemographic and behavioural characteristics}

Area of residence was classified as urban, rural or remote based on an index of distance to the nearest urban centre $^{27}$. Occupation was classified as manager; professional; associate professional/trades person; advanced sales, clerical or personal service; intermediate sales/ clerical/service; intermediate production/elementary clerical; labourer/related; or no paid job/other ${ }^{28}$. Living arrangement was classified as living alone, with partner only, with children only, with partner and children, or with others (not partner/children).

Health-related variables included menopause status, which was defined on the basis of self-report of menstrual bleeding: no menstrual bleeding in the last 12 months (postmenopausal); menstrual bleeding in the last 12 months, but not in the last 3 months or with different menstrual frequency compared with the previous year (perimenopausal); menstrual bleeding in the last 3 months and in the last 12 months and with the same frequency as in the previous year (premenopausal); and women who had undergone a hysterectomy. Body mass index (BMI) was calculated from self-reported height and weight (as weight in $\mathrm{kg}$ divided by the square of height in $\mathrm{m}$ ). BMI was categorised as underweight $\left(\mathrm{BMI}<20 \mathrm{~kg} \mathrm{~m}^{-2}\right.$ ), healthy weight $\left(\mathrm{BMI}=20-25 \mathrm{~kg} \mathrm{~m}^{-2}\right)$, overweight $\left(\right.$ BMI $\left.>25-30 \mathrm{~kg} \mathrm{~m}^{-2}\right)$ or obese $\left(\text { BMI }>30 \mathrm{~kg} \mathrm{~m}^{-2}\right)^{29}$. Physical activity scores were derived from self-reported duration and intensity of activity ${ }^{30}$. Scores were categorised as none, low, moderate or high levels of physical activity in the last week. Cigarette smoking status was defined as never smoker, ex-smoker, and light, moderate or heavy smoker $\left(<10,10-20\right.$ and $>20$ cigarettes day $^{-1}$, respectively).

\section{Statistical analysis}

Chi-square tests were used to analyse differences in proportions of women meeting each of the guidelines, by sociodemographic and health variables. Logistic regression modelling was used to estimate crude and adjusted odds ratios ( $95 \%$ confidence intervals) for women who met at least seven of the 13 guidelines. In the final model, odds ratios were adjusted for sociodemographic, biological and behavioural characteristics (occupation, area of residence, living arrangement, menopause status, BMI, smoking status and physical activity level).

\section{Results}

Table 1 shows the sociodemographic, biological and behavioural characteristics of the women in Survey 3 . More than half of the women (53-92\%) met the dietary guidelines for vegetables/legumes, fruit, meat/fish/poultry etc., 'extra' foods, alcohol, sugar, sodium and calcium (Tables 2 and 3). In contrast, less than one-third met the guidelines for bread/cereal-based foods, milk/ yoghurt/cheese, total/saturated fat intake and iron intake.

Compliance with many of the individual recommendations varied significantly across sociodemographic, biological and lifestyle variables. Among occupation groups, women who worked as labourers were less likely to meet recommendations for vegetables/legumes, fruit, 'extra' foods, low fat and saturated fat and sodium. Managers were less likely to meet the milk/yoghurt/cheese recommendation. Professionals were most likely to meet the highest number of guidelines. Women living in urban areas were least likely to meet the vegetables/legumes recommendation, whereas women living in rural and remote areas were least likely to meet guidelines for fruit, total fat and saturated fat and sodium. Women living alone, or with people other than a partner and children, were less likely to meet recommendations for vegetables/legumes and meat consumption, and calcium intake. However, those living alone were more likely to meet guidelines with respect to consumption of 'extra' foods, and total/saturated fat and sodium intake. Women living with a partner and children were most likely to meet guidelines for vegetables/legumes and meat consumption, and sugar intake.

Compliance was also found to vary by health-related factors. For example, women who had undergone a hysterectomy were more likely to meet the vegetables/ legumes guideline. Current smokers, particularly moderate and heavy smokers, were least likely to comply with dietary guidelines, except those for sodium intake, which did not vary by smoking status, or for sugars, which they were most likely to meet. Women in the healthy-weight 
Table 1 Sociodemographic and behavioural characteristics of middle-aged women at Survey 3 in 2001

\begin{tabular}{|c|c|}
\hline Sociodemographic or behavioural characteristic & Percentage $^{*}$ \\
\hline \multicolumn{2}{|l|}{ Occupation } \\
\hline Manager & 8 \\
\hline Professional & 20 \\
\hline Associate professional/trades person & 10 \\
\hline Advanced sales, clerk or personal service & 10 \\
\hline Intermediate sales, clerk or personal service & 13 \\
\hline Intermediate production, elementary clerical service & 5 \\
\hline Labourer & 8 \\
\hline No paid job/other & 26 \\
\hline \multicolumn{2}{|l|}{ Area of residence } \\
\hline Urban & 38 \\
\hline Rural & 57 \\
\hline Remote & 5 \\
\hline \multicolumn{2}{|l|}{ Living arrangement } \\
\hline Alone & 9 \\
\hline With partner only & 50 \\
\hline With children only & 8 \\
\hline With partner and children only & 31 \\
\hline With others (not partner/children) & 2 \\
\hline \multicolumn{2}{|l|}{ Marital status } \\
\hline Married/de facto relationship & 76 \\
\hline Separated/divorced/widowed & 20 \\
\hline Single & 4 \\
\hline \multicolumn{2}{|l|}{ Menopause status } \\
\hline Premenopausal & 14 \\
\hline Perimenopausal & 24 \\
\hline Postmenopausal & 33 \\
\hline Hysterectomy & 29 \\
\hline \multicolumn{2}{|l|}{ Body mass index } \\
\hline Underweight $\left(<20 \mathrm{~kg} \mathrm{~m}^{-2}\right)$ & 5 \\
\hline Healthy weight $\left(20-25 \mathrm{~kg} \mathrm{~m}^{-2}\right)$ & 39 \\
\hline Overweight $\left(>25-30 \mathrm{~kg} \mathrm{~m}^{-2}\right)^{\prime}$ & 32 \\
\hline Obese $\left(>30 \mathrm{~kg} \mathrm{~m}^{-2}\right)$ & 24 \\
\hline \multicolumn{2}{|l|}{ Smoking behaviour } \\
\hline Never smoker & 58 \\
\hline Ex-smoker & 27 \\
\hline Light smoker $\left(<10\right.$ cigarettes day $\left.^{-1}\right)$ & 5 \\
\hline Moderate smoker $\left(10-20\right.$ cigarettes day $\left.{ }^{-1}\right)$ & 5 \\
\hline Heavy smoker $\left(>20\right.$ cigarettes day $\left.{ }^{-1}\right)$ & 5 \\
\hline \multicolumn{2}{|l|}{ Physical activity in the last week } \\
\hline None & 18 \\
\hline Low & 37 \\
\hline Moderate & 20 \\
\hline High & 25 \\
\hline
\end{tabular}

*Out of a maximum total of 10561 women, although numbers varied slightly for some variables due to missing values.

range were more likely to meet guidelines for fruit consumption, and saturated fat and sodium intakes. Conversely, obese women were least likely to meet these guidelines and that for milk/yoghurt/cheese consumption. Women who did no physical activity were less likely to meet all individual guidelines except those for alcohol and sodium intake, which did not vary by activity level, and sugars, which they were most likely to meet.

Approximately 41\% (4290/10 561) of women met at least half (seven or more) of the guidelines examined (i.e. 'overall compliers'). Results of the fully-adjusted multiple logistic regression model showed the likelihood of overall compliance to differ significantly by occupation, living arrangement, BMI category, smoking behaviour and physical activity (Table 4). Compared with women in professional occupations, women in all other occupational groups were less likely to be overall compliers. Compared with women living with a partner only, those living with 'others' were less likely to be overall compliers. Both smoking and physical activity showed strong positive associations with the likelihood of compliance, with women who were heavy smokers and those doing no physical activity least likely to be overall compliers.

\section{Discussion}

This paper describes key aspects of the diets of Australian women in relation to current Australian dietary guidelines and policy on healthy eating ${ }^{4}$. It provides data on recent food habits and dietary intakes in a large communitybased sample of middle-aged Australian women, since the development and promotion of The Australian Guide to Healthy Eating ${ }^{4}$.

It should be acknowledged that it was not possible to assess precise numbers of food servings in the present study. Nevertheless, based on statistical analyses of frequency of daily consumption, most women (92\%) from the ALSWH appeared to meet the dietary guideline for consumption of meat/fish/poultry etc. (i.e. expected to have adequate protein intake), while $71 \%$ met the guideline for 'extra' foods. However, for every other dietary guideline examined, large percentages of women (ranging from 32\% for alcohol to $88 \%$ for bread/cereals) did not meet the recommendation. When the dietary recommendations investigated here were considered as a whole, only $41 \%$ of women met at least one-half (seven or more). Further analyses (not shown) demonstrated that the diets of only two women in the entire sample of 10561 met all 13 recommendations.

It is not known how many women in this sample were aware of or actively trying to consume a diet consistent with dietary guidelines. None the less, these findings suggest that current recommendations may be unachievable for many women. Much more effort must be directed towards understanding the reasons why Australian women's diets fall short of meeting dietary recommendations, and facilitating improvement of their diets. Such efforts may also involve the revision of existing guidelines and the development of more realistic 'intermediate' guidelines as a stepwise approach to achieving the recommendations currently promoted for good health ${ }^{31}$.

Certain sociodemographic subgroups of women, particularly those who worked in labouring occupations and those who lived with persons other than a partner or children, were least likely to follow dietary recommendations, either individually or when assessed as 'overall compliance'. These findings are consistent with previous Australian and international evidence of poorer dietary quality or compliance with guidelines among individuals in lower-status occupations $s^{7,32}$ and among those living alone 


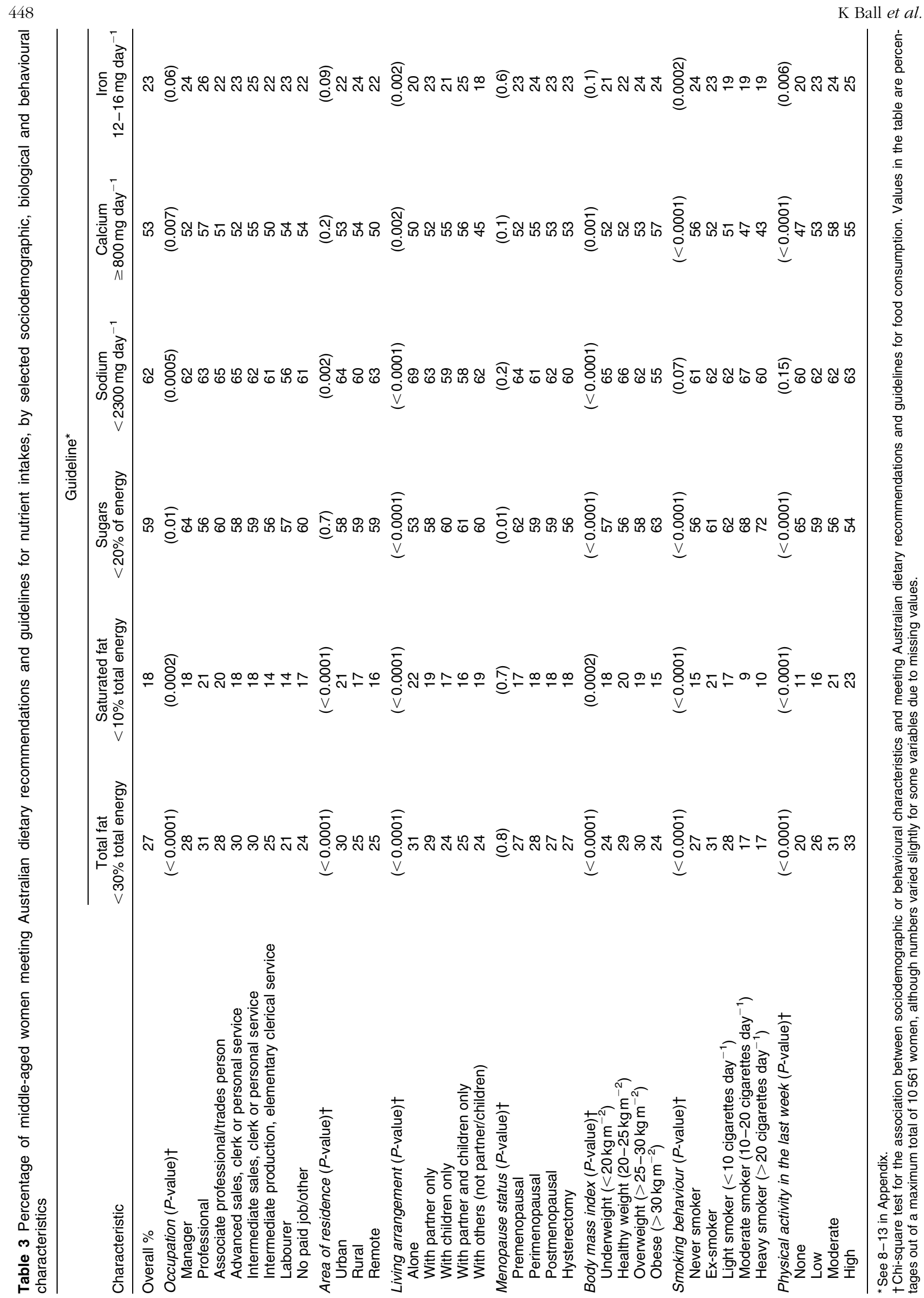


Table 4 Odds ratio $(95 \%$ confidence interval $(\mathrm{Cl}))$ for women who met at least seven of 13 Australian dietary recommendations and guidelines for food consumption and nutrient intake

\begin{tabular}{|c|c|c|c|}
\hline Characteristic & $\%$ of women ${ }^{*}$ & Crude odds ratio $(95 \% \mathrm{Cl})$ & $\begin{array}{c}\text { Adjusted } \\
\text { odds ratio }(95 \% \mathrm{Cl}) \dagger\end{array}$ \\
\hline \multicolumn{4}{|l|}{ Occupation } \\
\hline Professional & 51 & Reference & Reference \\
\hline Manager & 40 & $0.6(0.5-0.8)$ & $0.7(0.6-0.9)$ \\
\hline Associate professional/trades person & 42 & $0.7(0.6-0.8)$ & $0.8(0.6-0.9)$ \\
\hline Advanced sales, clerk or personal service & 42 & $0.7(0.6-0.8)$ & $0.7(0.6-0.8)$ \\
\hline Intermediate sales, clerk or personal service & 42 & $0.7(0.6-0.8)$ & $0.7(0.6-0.9)$ \\
\hline Intermediate production, elementary clerical service & 37 & $0.6(0.5-0.7)$ & $0.6(0.4-0.7)$ \\
\hline Labourer & 31 & $0.4(0.4-0.5)$ & $0.5(0.4-0.6)$ \\
\hline No paid job/other & 37 & $0.6(0.5-0.7)$ & $0.6(0.5-0.7)$ \\
\hline \multicolumn{4}{|l|}{ Area of residence } \\
\hline Urban & 42 & Reference & Reference \\
\hline Rural & 40 & $0.9(0.8-1.0)$ & $1.0(0.9-1.1)$ \\
\hline Remote & 39 & $0.9(0.7-1.0)$ & $0.9(0.8-1.2)$ \\
\hline \multicolumn{4}{|l|}{ Living arrangement } \\
\hline With partner only & 41 & Reference & Reference \\
\hline Alone & 41 & $1.0(0.9-1.2)$ & $1.0(0.9-1.2)$ \\
\hline With children only & 39 & $0.9(0.8-1.1)$ & $0.9(0.8-1.2)$ \\
\hline With partner and children only & 42 & $1.1(1.0-1.2) \ddagger$ & $1.0(0.9-1.1)$ \\
\hline With others (not partner/children) & 33 & $0.7(0.5-1.0) \ddagger$ & $0.7(0.5-1.0) \ddagger$ \\
\hline \multicolumn{4}{|l|}{ Menopause status } \\
\hline Premenopausal & 39 & Reference & Reference \\
\hline Perimenopausal & 44 & $1.2(1.1-1.4)$ & $1.3(1.1-1.5)$ \\
\hline Postmenopausal & 41 & $1.1(0.9-1.2)$ & $1.2(1.0-1.3)$ \\
\hline Hysterectomy & 39 & $1.0(0.9-1.1)$ & $1.1(0.9-1.3)$ \\
\hline \multicolumn{4}{|l|}{ Body mass index } \\
\hline Underweight $\left(<20 \mathrm{~kg} \mathrm{~m}^{-2}\right)$ & 43 & Reference & Reference \\
\hline Healthy weight $\left(20-25 \mathrm{~kg} \mathrm{~m}^{-2}\right)$ & 40 & $0.9(0.7-1.1)$ & $0.9(0.7-1.1)$ \\
\hline Overweight $\left(>25-30 \mathrm{~kg} \mathrm{~m}^{-2}\right)^{\prime}$ & 43 & $1.0(0.9-1.1)$ & $1.1(0.9-1.2)$ \\
\hline Obese $\left(>30 \mathrm{~kg} \mathrm{~m}^{-2}\right)$ & 37 & $0.8(0.7-0.9)$ & $0.9(0.8-1.0) \ddagger$ \\
\hline \multicolumn{4}{|l|}{ Smoking behaviour } \\
\hline Never smoker & 43 & Reference & Reference \\
\hline Ex-smoker & 42 & $1.0(0.9-1.1)$ & $0.9(0.8-1.0)$ \\
\hline Light smoker $\left(<10\right.$ cigarettes day $\left.{ }^{-1}\right)$ & 34 & $0.7(0.6-0.9)$ & $0.6(0.5-0.8)$ \\
\hline Moderate smoker $\left(10-20\right.$ cigarettes $^{\prime}$ day $\left.^{-1}\right)$ & 30 & $0.6(0.5-0.7)$ & $0.6(0.5-0.8)$ \\
\hline Heavy smoker $\left(>20\right.$ cigarettes day $\left.{ }^{-1}\right)$ & 26 & $0.5(0.4-0.6)$ & $0.5(0.4-0.7)$ \\
\hline \multicolumn{4}{|l|}{ Physical activity in the last week } \\
\hline None & 28 & Reference & Reference \\
\hline Low & 39 & $1.6(1.4-1.8)$ & $1.5(1.3-1.7)$ \\
\hline Moderate & 47 & $2.2(2.0-2.5)$ & $1.9(1.7-2.2)$ \\
\hline High & 48 & $2.3(2.0-2.6)$ & $2.0(1.8-2.4)$ \\
\hline
\end{tabular}

or with others, as opposed to living with a partner/ spouse $^{33,34}$ and/or children ${ }^{35}$. Interestingly, the only dietary recommendation that did not vary across occupation group, area of residence, menopause status or BMI category related to iron intake. Less than one-quarter of the sample met the recommendation for iron intake. This finding demonstrates that sub-optimal iron intake is widespread among middle-aged Australian women, despite $92 \%$ meeting the guideline for the consumption of meat/fish/poultry etc., with all sociodemographic groups at risk.

Women who currently smoked (particularly moderate and heavy smokers), those who reported low levels of physical activity and, for several guidelines, those who were obese were also at greatest risk of non-compliance with dietary guidelines. These findings support the notion of a 'clustering' of poor health behaviours that has been reported previously ${ }^{36,37}$. These findings are of particular concern, since the risk of nutrition-related health problems among those women with the poorest diets is likely to be compounded by increased risk of morbidity and mortality associated with their smoking ${ }^{38}$, physical inactivity ${ }^{39}$ and obesity ${ }^{40}$.

The findings of subgroup variations for the guideline on sugar intake deserve some consideration. Unlike many of the other guidelines, women who were smokers, obese and inactive were more likely to meet this guideline. This is likely to be related to the inability 
in the present study to distinguish natural sugars (e.g. those found in fruit) from refined/processed sugars, the latter being the target of this guideline. The higher likelihood of these particular groups to meet the guideline of $<20 \%$ total energy intake from sugar may reflect their lower likelihood to consume fruit, and hence their lower intake of natural sugars. To further examine the unexpected findings for sugar, supplementary analyses investigated responses to an additional question on daily consumption of added (refined) sugar, for instance in tea, coffee or on breakfast cereals (results not shown). Smokers and inactive women, as well as women in labouring occupations and women living in remote locations, were found to be most likely to consume added sugar. This supports the hypothesis that the findings for the guideline on total sugar relate to variations in the intake of natural rather than processed/added sugar.

Previous studies of Australian diets have concluded that intakes have improved over recent decades in directions consistent with many of the dietary guidelines. For example, a comparison of 1983 and 1995 national nutrition surveys in Australia showed notable increases in intakes of calcium and iron ${ }^{15}$, two nutrients introduced into the guidelines. Data from earlier regional and national dietary surveys ${ }^{11,13,41-43}$ also suggest a decrease in total fat intake in the Australian population, from around $40 \%$ of total energy intake in the late 1970 s to $32-34 \%$ in the early 1990 s, as well as consistent decreases in saturated fat intakes.

While these trends are promising, the present findings suggest that Australian women are still a long way from consuming diets considered optimal for health. This is consistent with previous Australian ${ }^{13,14,44}$ and international ${ }^{31,35,45}$ findings. For example, the $1995 \mathrm{NNS}^{13,14}$ also showed that dietary intakes of large percentages of the population were not congruent with the dietary recommendations. For instance, 78\% of women responding to the NNS ate less than four servings of vegetables and $45 \%$ ate less than two servings of fruit/fruit-containing foods per day. Mean/median intakes of fat, saturated fat and sugars were above recommended levels, and calcium and iron intakes below recommended levels. No national data exist on salt intake for Australians, although a Tasmanian study of 194 adults showed that only 36\% of women had sodium intakes below the recommended daily maximum level of $2300 \mathrm{mg}^{44}$. In the USA, data from the second National Health and Nutrition Examination Survey (NHANES II) showed that only 10\% of the sample consumed the recommended five or more servings of fruit and vegetables daily ${ }^{45}$.

Several strengths of the present study lend credence to the findings. These include the use of a comprehensive, previously validated $\mathrm{FFQ}^{24,25}$ and the large, representative population sample of middle-aged women from a range of sociodemographic backgrounds. However, the generalisability of the findings to other age groups and to men is unknown. The inability of the FFQ method used in this study to provide a precise assessment of number of servings, and the potential for dietary underreporting to affect estimates of food consumption and nutrient intake, is acknowledged.

The present findings demonstrate that a considerable disparity exists between Australian dietary recommendations and the actual diets of middle-aged Australian women. It remains for future studies to determine the reasons for this gap. Speculatively, both cognitive and structural factors (e.g. knowledge/awareness, poor access to fresh foods) may act as barriers to compliance with dietary guidelines. A recent American study found that consumer knowledge and understanding of dietary guidelines was quite poor, with on average less than two-and-a-half of a total of 13 guidelines recalled and participants having difficulties with their interpretation ${ }^{46}$.

Mechanisms underlying subgroup differences in diet also require further investigation. A recent Australian study showed that financial and storage problems were key barriers to achieving adequate fruit and vegetable consumption among people of lower socio-economic status ${ }^{47}$. Women of lower socio-economic status may also be less aware of the guidelines. In terms of differences by living arrangements, women living with a partner and/or children may make more effort to comply with guidelines since they are responsible for the diets of other family members. A better understanding of the reasons for different women not meeting dietary guidelines is crucial for informing public health programmes and policies, and for the setting of future guidelines - possibly incorporating a stepwise approach ${ }^{31}$ - aimed at improving women's nutrition and health.

\section{Acknowledgements}

The Australian Longitudinal Study on Women's Health, which was conceived and developed by groups of interdisciplinary researchers at the universities of Newcastle and Queensland, is funded by the Commonwealth Department of Health and Ageing. We thank all participants for their valuable contribution to this project. K.B. is supported by a Public Health Postdoctoral Research Fellowship from the National Health and Medical Research Council, ID 136925. Part of the research for this paper was conducted while K.B. was a visiting researcher at MRC Human Nutrition Research, Cambridge, UK. We thank the Australian National Health and Medical Research Council, and the UK Medical Research Council, for funding this research visit. The authors thank Professor Graham Giles of the Cancer Epidemiology Centre of The Cancer Council of Victoria for permission to use the Dietary Questionnaire for Epidemiological Studies, version 2 (The Cancer Council of Victoria, Melbourne, Australia, 1996). 


\section{References}

1 World Health Organization (WHO). Diet, Nutrition and the Prevention of Chronic Diseases. Technical Report Series No. 797. Geneva: WHO, 1990.

2 Department of Health. Dietary Reference Values for Food Energy and Nutrients for the United Kingdom. Report on Health and Social Subjects No. 41. London: HMSO, 1991.

3 National Health and Medical Research Council. Dietary Guidelines for Australian Adults. Canberra: Australian Government Printing Service, 2003.

4 Smith A, Kellett E, Schmerlaib Y. The Australian Guide to Healthy Eating. Canberra: Commonwealth Department of Health and Family Services, 1998.

5 Worsley A, Crawford D. Awareness and compliance with the Australian dietary guidelines: a descriptive study of Melbourne residents. Nutrition Research 1985; 5: 1291-308.

6 Worsley A, Crawford D. Who complies with the Australian dietary guidelines? Nutrition Research 1986; 6: 29-34.

7 Baghurst KI, Record SJ, Baghurst PA, Syrette JA, Crawford DA, Worsley A. Socio-demographic determinants in Australia of the intake of food and nutrients implicated in cancer aetiology. Medical Journal of Australia 1990; 153: 444-52.

8 Jamison JR. Australian dietary targets in 1995: their feasibility and pertinence to dietary goals for 2000. Australian Journal of Public Health 1995; 19: 522-24.

9 Turrell G. Compliance with the Australian dietary guidelines in the early 1990s: have population-based health promotion programs been effective? Nutrition and Health 1997; 11: $271-88$.

10 Woodward D. Dietary variation within the Australian community: differing food choices in the state capital cities. Australian Journal of Nutrition and Dietetics 1990; 47: 3-7.

11 Commonwealth Department of Community Services and Health. National Dietary Survey of Adults: 1983. No. 2 Nutrient Intakes. Canberra: Australian Government Printing Service, 1987.

12 Lester IH. Australia's Food \& Nutrition. Canberra: Australian Government Printing Service, 1994.

13 Australian Bureau of Statistics (ABS). National Nutrition Survey: Nutrient Intakes and Physical Measurements, Australia. Catalogue No. 4805.0. Canberra: ABS, 1998.

14 Australian Bureau of Statistics (ABS). National Nutrition Survey: Foods Eaten, Australia. Catalogue No. 4804.0. Canberra: ABS, 1999.

15 Cook T, Rutishauser IHE, Seelig M. Comparable Data on Food and Nutrient Intake and Physical Measurements from the 1983, 1985 and 1995 National Nutrition Surveys. Canberra: Commonwealth Department of Health and Aged Care, 2001.

16 Marks GC, Rutishauser IHE, Webb K, Picton P. Key Food and Nutrition Data for Australia 1990-1999. Canberra: Australian Food and Nutrition Monitoring Unit, 2001.

17 National Health and Medical Research Council. Recommended Dietary Intakes for use in Australia. Canberra: Australian Government Printing Service, 1991.

18 National Health and Medical Research Council. Is There a Safe Level of Daily Consumption of Alcohol for Men and Women? Recommendations Regarding Responsible Drinking Behaviour. Canberra: Australian Government Printing Service, 1991

19 National Health and Medical Research Council. The Role of Polyunsaturated Fats in the Australian Diet. Canberra: Australian Government Printing Service, 1991.

20 National Health and Medical Research Council. Dietary Guidelines for Australians. Canberra: Australian Government Printing Service, 1992.

21 Brown WJ, Bryson L, Byles JE, Dobson AJ, Lee C, Mishra G, et al. Women's Health Australia: recruitment for a national longitudinal cohort study. Women \& Health 1998; 28: 23-40.

22 Mihelic AH, Crimmins EM. Loss to follow-up in a sample of
Americans 70 years of age and older: the LSOA 1984-1990. Journal of Gerontology: Social Sciences 1997; 52: S37-48.

23 Singh C. A Comparative Analysis of Attrition in Household Panel Studies [online]. PACO Document No. 10. Differdange, Belgium: CEPS/INSTEAD, 1995. Available at http://www. ceps.lu/paco/pacopub.htm.

24 Ireland P, Jolley D, Giles G, O'Dea K, Powles J, Rutishauser I, et al. Development of the Melbourne FFQ: a food frequency questionnaire for use in an Australian prospective study involving an ethnically diverse cohort. Asia Pacific Journal of Clinical Nutrition 1994; 3: 19-31.

25 Hodge A, Patterson AJ, Brown WJ, Ireland P, Giles G. The Anti Cancer Council of Victoria FFQ: relative validity of nutrient intakes compared with weighed food records in young to middle-aged women in a study of iron supplementation. Australian and New Zealand Journal of Public Health 2000; 24: 576-83.

26 Department of Community Services and Health. Composition of Foods, Australia. Canberra: Australian Government Publishing Service, 1989.

27 Department of Primary Industries and Energy, Department of Human Services and Health. Rural, Remote and Metropolitan Areas Classification: 1991 Census Edition. Canberra: Australian Government Publishing Service, 1994.

28 Australian Bureau of Statistics. Australian Standard Classification of Occupations (ASCO). 2nd ed. Catalogue No. 1220.0. Canberra: Australian Government Publishing Service, 1997.

29 National Health and Medical Research Council. Acting on Australia's Weight: A Strategic Plan for the Prevention of Overweight and Obesity. Canberra: Australian Government Publishing Service, 1997.

30 Brown WJ, Bauman AE. Comparison of estimates of population levels of physical activity using two measures. Australian and New Zealand Journal of Public Health 2000; 24: $520-5$.

31 Wearne SJ, Day MJ. Clues for the development of food-based dietary guidelines: how are dietary targets being achieved by UK consumers? British Journal of Nutrition 1999; 81(Suppl. 2): S119-26.

32 Bolton-Smith C, Brown CA, Tunstall-Pedoe H. Nutrient sources in non-manual and manual occupational groups: results from the Scottish Heart Health Study (SHHS). Journal of Human Nutrition and Dietetics 1991; 4: 291-306.

33 Billson H, Pryer JA, Nichols R. Variation in fruit and vegetable consumption among adults in Britain: an analysis from the Dietary and Nutritional Survey of British Adults. European Journal of Clinical Nutrition 1999; 53: 946-52.

34 Davis MA, Murphy SP, Neuhaus JM, Gee L, Quiroga SS. Living arrangements affect dietary quality for US adults aged 50 years and older: NHANES III 1988-1994. Journal of Nutrition 2000; 130: 2256-64.

35 Roos E, Lahelma E, Virtanen M, Prattala R, Pietinen P. Gender, socioeconomic status and family status as determinants of food behaviour. Social Science \& Medicine 1998; 46: 1519-29.

36 English RM, Najman JM, Bennett SA. Dietary intake of Australian smokers and nonsmokers. Australian and New Zealand Journal of Public Health 1997; 21: 141-6.

37 Schuit AJ, van Loon AJ, Tijhuis M, Ocke M. Clustering of lifestyle risk factors in a general adult population. Preventive Medicine 2002; 35: 219-24.

38 US Department of Health, Education, and Welfare. Smoking and Health: Report of the Advisory Committee to the Surgeon General of the Public Health Service. Washington, DC: US Government Printing Office, 1964.

39 US Department of Health and Human Services (DHHS). Physical Activity and Health: A Report of the Surgeon General. Atlanta, GA: US DHHS, Centers for Disease Control 
and Prevention, National Center for Chronic Disease Prevention and Health Promotion, 1996.

40 World Health Organization (WHO). Obesity: Preventing and Managing the Global Epidemic. Geneva: WHO, 1997.

41 Baghurst KI, Worsley A, Crawford DA, Baghurst PA, Record SJ, Syrette JA. The Victorian Nutrition Survey 1985. Adelaide: Social Nutrition and Epidemiology Programme, CSIRO Division of Human Nutrition, 1987.

42 Baghurst KI, Record SJ, Syrette JA, Baghurst PA. The Victorian Nutrition Survey 1990. Adelaide: Social Nutrition and Epidemiology Programme, CSIRO Division of Human Nutrition, 1991.

43 Baghurst KI, Baghurst PA, Record SJ. Demographic and dietary profiles of high and low fat consumers in Australia Journal of Epidemiology and Community Health 1994; 48 $26-32$.
44 Beard TC, Woodward DR, Ball PJ, Hornsby H, von Witt RJ, Dwyer T. The Hobart Salt Study 1995: few meet national sodium intake target. Medical Journal of Australia 1997; 166: $404-7$.

45 Block G. Dietary guidelines and the results of food consumption surveys. American Journal of Clinical Nutrition 1991; 53(suppl. 1): 356S-7S.

46 Keenan DP, AbuSabha R, Robinson NG. Consumers' understanding of the Dietary Guidelines for Americans: insights into the future. Health Education \& Behavior 2002; 29: $124-35$.

47 Giskes K, Turrell G, Patterson C, Newman B. Socioeconomic differences in fruit and vegetable consumption among Australian adolescents and adults. Public Health Nutrition 2002; 5: 663-9.

\section{Appendix - Dietary recommendations/guidelines for adults and indicators used*}

Recommendation/guideline Indicator

$1 \quad$ Eat plenty of bread and cereals: at least four servings per day are recommended by The Australian Guide to Healthy Eating

2 Eat plenty of vegetables (including legumes): five or more servings daily

3 Eat plenty of fruit: two or more servings daily

4 Milk/yoghurt/cheese: eat two or more servings daily

5 Meat/fish/poultry/eggs/nuts/legumes: eat one or more servings daily

6 'Extra' foods: two-and-a-half or fewer servings daily

7 If you drink alcohol, limit your intake (two or fewer drinks per day)

8 Eat a diet low in fat ( $<30 \%$ total energy)

9 Eat a diet low in saturated fat $(<10 \%$ total energy)

10 Eat only a moderate amount of sugars and foods containing added sugars (no levels specified for adults, but an average intake of $15-20 \%$ of energy as sugar is suggested for older adults)

11 Choose low-salt foods and use salt sparingly $\left(<2300 \mathrm{mg}\right.$ sodium day $\left.{ }^{-1}\right)$

12 Eat foods containing calcium $\left(\geq 800 \mathrm{mg} \mathrm{day}^{-1}\right)$

13 Eat foods containing iron (12-16 $\left.\mathrm{mg} \mathrm{day}^{-1}\right)$
Any four or more items selected from: bread, breakfast cereal, porridge, muesli, pasta, noodles, rice, crackers/crispbread/dry biscuits

Any five or more items selected from: potatoes cooked without fat, fresh or tinned tomatoes, tomato sauce, tomato paste or dried tomatoes, capsicum, lettuce, cucumber, celery, beetroot, carrots, cabbage, Brussels sprouts, cauliflower, broccoli, silverbeet, spinach, peas, green beans, alfalfa sprouts, baked beans, soybeans/soybean curd/tofu, other beans, pumpkins, onion, leeks, garlic, mushrooms, zucchini

Any two or more items selected from: oranges/citrus fruit, apples, pears, bananas, watermelon, rockmelon, honeydew melon, pineapple, strawberries, apricots, peaches/nectarines, mango, paw paw, avocado, tinned or frozen fruit, fruit juice

Any two or more items selected from: milk/flavoured milk, yoghurt, cheese

Any one or more item(s) selected from: beef, veal, lamb, pork, bacon, ham, chicken, processed meat, sausages, fish - steamed, grilled or baked, fish - tinned, nuts, peanut butter/paste, baked beans, soybeans/soybean curd/tofu, other beans

Two-and-a-half items selected from: ice cream, sweet biscuits, chocolate, cakes, sweet pies, tarts, other sweet pastries, corn chips, potato crisps, Twisties ${ }^{\mathrm{TM}}$ etc., potatoes roasted or fried, fish fried including take-away fish, pizza, hamburger, meat pies, pasties, quiche and other savoury pastry, soft drinks, beer (full-strength or low-alcohol), wine (red or white), fortified wines, port, sherry, spirits, liqueurs, etc.

Fewer than two standard drinks selected from: beer (full-strength or low-alcohol), wine (red or white), fortified wines, port, sherry, spirits, liqueurs, etc.

Calculated from nutrient estimates

Calculated from nutrient estimates

Calculated from nutrient estimates

Calculated from nutrient estimates

Calculated from nutrient estimates

Calculated from nutrient estimates

Sources of dietary recommendations/guidelines: 1-6, ref. 4; 7, 12 and 13, refs 17 and 20; 8 and 9, refs 18 and 20; 10 and 11 , ref. 20 .

${ }^{*}$ Although the food-based Australian Dietary Guidelines have recently been updated ${ }^{3}$, these analyses focus on those guidelines that were current at the time of the survey ${ }^{4,20}$. The key features of these guidelines have not changed substantially with the recent revisions. 